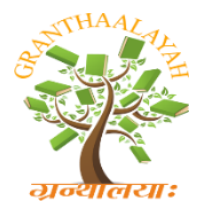

\author{
INTERNATIONAL JOURNAL OF RE
GRANTHAALAYAH \\ A knowledge Repository
}

Science

\title{
MATERNAL RISK FACTORS IN ADOLESCENTS WITH THREAT OF PRETERMINE BIRTH IN ENRIQUE SOTOMAYOR HOSPITAL
}

\author{
Obst. Yesica Pazmiño Mera, MSc ${ }^{1}$, Dr. Jorge Daher Nader PhD ${ }^{2}$, Dr. Miguel Gonzalez \\ Pluas $^{3}$, MSc. Cecilia Herrera Martinez ${ }^{4}$, Obsta. Rocio Fonseca MSc ${ }^{5}$, Obsta.Vicky Narea \\ Morales MSc ${ }^{6}$ \\ 1,2, 3, 4, 5, 6 Teachers of The Career of Obstetrics of The Faculty of Medical Sciences of The \\ University of Guayaquil-Ecuador
}

\begin{abstract}
It is vitally important to understand that premature birth at the Latin American level and in Ecuador is a Public Health problem is considered as one of the main causes of perinatal morbidity and mortality, determined by certain obstetric gynecological aspects such as newborn weight, gestational age is important when there is an irregularity of gestational development when not being found within 32 weeks they produce a greater rate of neonatal morbidity and mortality as a consequence a greater percentage of sequelae; Therefore, it is important that through the present study it is understood that the incidence of premature births should be reduced, which not only affects the pregnant woman but also the newborn. This research is quantitative, non-experimental, cross-sectional with a descriptive level of research, based on the medical records of patients between the ages of 10 and 19 treated at the Enrique C. Sotomayor hospital in Guayaquil in the period 2015 When the present study is carried out, it is concluded that since there is no consistent prenatal control on the part of pregnant women, it directly influences the pre-term delivery leading to this problem to establish a high predisposition to produce maternal-neonatal morbidity and mortality; a greater awareness campaign should be carried out regarding the prenatal controls necessary to reduce the incidence of preterm birth. The age group with the greatest predisposition is established in adolescents whose age range is from 17 to 19 years.
\end{abstract}

Keywords: Pretermine; Preclampsy; RPM.

Cite This Article: Yesica pazmiño Mera, Dr. Jorge Daher Nader, Dr. Miguel Gonzalez Pluas, Cecilia Herrera Martinez, Rocio Fonseca, and Vicky Narea Morales. (2020). "MATERNAL RISK FACTORS IN ADOLESCENTS WITH THREAT OF PRETERMINE BIRTH IN ENRIQUE SOTOMAYOR HOSPITAL." International Journal of Research - Granthaalayah, 8(2), 124-133. https://doi.org/10.29121/granthaalayah.v8.i2.2020.193.

\section{Introduction}

It is known that preterm birth has been eventually placed in the 37-week gestation timeframe as indicated by WHO - 1970-77, where the lower limit parameter of this gestational age establishes 
an appeal point to locate a limit in preterm birth, in the case of abortion according to WHO, is within 22 weeks of the gestation process, which takes into account the figures of $500 \mathrm{~g}$ according to the weight or $25 \mathrm{~cm}$ of crown at tailbone for the As a result, the certainly adverse effects established clinically for a pre-labor stay to be delivered are very rare, so it is taken into account that uterine contractions in continuity with lapses of 1 to 10 minutes, thus with a margin of 30 seconds of duration with respect to the erasure of the neck by $50 \%$, and, it is found with a dilation of equal or lesser extent at $3 \mathrm{~cm}$; Some of these symptomatic instances can be conceptualized as a childbirth of imminent nature, the meaning in preterm delivery or high-risk premature $\mathrm{RN}$, is itself referred to with reference to the fact that the born child does not have an optimal development when completing the 32 weeks, which in many cases is already foreseen as an adequate time in the complete development of pregnancy, which is why this is an essential factor for a clinical management of the time that is within 23 to 24 weeks; in these cases, the existence of a gestational age that does not respect the appropriate development time must be taken into account and also very thorough, analysis and an exhaustive case must be carried out with the respective follow-ups, within the corresponding 32 weeks of gestation, here we find a $15 \%$ that is based on a total PP limit that may have a higher perinatal risk, therefore, in such cases, prevention methods and the appropriate follow-up control should be applied for the classification of this type of pregnancy ( MINSA 2011)

According to the WHO, 2012 each year there are established percentages of mothers aged between 15 and 19, who give birth to a total of 16 million products, this in turn represents in the largest of instances $11 \%$ in reference to deliveries worldwide, $95 \%$ to what equivalents in these deliveries are within the range for countries with a low or middle income economy, consequently, most of the adolescent of middle-income countries exceeds in greater instance to those of countries that have a high income, in turn the countries with low income reach a figure that is five times higher than that of the middle and upper classes; around the world it is taken into account that the rate that corresponds to premature births is equivalent to $12.5 \%$ of the world total in what corresponds to births, in countries like the United States, births reach high figures in certain ethnic groups, such as those of native groups In Africa with a tendency to a cup that corresponds to $17.5 \%$, Hispanics and non-Hispanic white women have certainly shown a value that could be maintained at the average margin; Latin America is based on $11 \%$ birth rates while the European continent has a figure of 5 to $7 \%$, obstetric care has not been able to decrease the high percentage in the last 40 years, so premature birth is It has become one of the causes of neonatal mortality in non-developing countries with responsibility for 60 to $80 \%$ of neonatal deaths, which has come to occupy the first place in this problem.

Premature births are a physical and medical condition of women, this would certainly be linked to pregnant women in adolescence which can be a primary factor for a preterm birth, factors such as emotional instability of the couple can also be attributed, poor parental control, and other cases that contribute to the risk of premature birth; Preterm birth is the major cause on which perinatal morbidity and mortality is based, this is based on some aspects such as the weight of the newborn and the developed gestational age, which plays an important role, the irregular development of pregnancy that is not find within 32 weeks of normal with greater neonatal morbidity and mortality and greater number of sequelae, prematurity itself is one of the main reasons why neonatal morbidity arises with childhood sequelae, this problem results in $70 \%$ mortality and $75 \%$ of morbidity; WHO establishes in 9.6\% what refers to births for the year 2005 on a premature basis, 
although this figure has been reduced from 12: $7 \%$ in 2017 to 12.3 in 2008, and what confers to 2019 until $12.1 \%$

These results are linked to the practices for optimal fertility, which are a factor to decrease some trigger that threatens the correct process of gestational development in pregnancy, and this in turn influences positively when making strategies to prevent recurrent premature births, worldwide it is a very short-term neonatal complication factor, because it has factors such as depression at birth, diseases that affect the correct respiratory process, interventricular hemorrhage, bacteria such as sepsis, metabolic disorders, necrotizing enterocolitis, ducts arterioses of persistent character, dysplasia bronchopulmonary or apnea in some cases, having cases that can result in cerebral palsy.

Regarding Matamala, 2014 indicates that among the factors with the highest mortality frequently identified are: multiple pregnant women, simultaneous chronic medical conditions, hypertension, diabetes, or infections that may occur during teenage pregnancy, so these instances of Risks are usually within the parameters of a preterm pregnancy that endangers the life of the mother and the fetus, on the other hand some sequelae and diseases that are developing can be a negative factor for the quality of life of the future newborn; According to Diaz, 2014, some of the different factors that put at risk are those presented by women who are pregnant during the period or period of pregnancy are: Infection of the tract, conditions of hypertensive syndrome of pregnancy (SHE), diseases such as Gestational diabetes mellitus, also due to consequences of premature rupture of the RPM membranes, hasty detachment of the placenta ormoinserta, DPPNI, intrauterine development delay or RCIU.

In Issler in the year 2011 the preterm birth was at 7\% scale, this percentage is similar to those found in multiple places that were equivalent to values between 5 to $10 \%$, consequently, the relationship that is had in the complications of pregnancy they are certainly cataloged to factors that have been associated with accelerated rupture of premature membranes, cervicovaginitis, gravidic hypermesis, urinary tract infections, and cases of anemia; by investigations carried out in the Provincial General Hospital of the city of Riobamba, it is established in $27.9 \%$ of cases with teenage pregnancies with a higher preterm birth rate, thus determining that the age within the adolescence regime is the factor by which can occur these cases of pregnancies; it was estimated that the highest number of cases of a preterm pregnancy occurs in the ages between 14 and 16 years of age, which in other instances were diagnosed with a percentage of $2.08 \%$ in relation to urinary tract infections, 12.5 In conditions of vaginosis, $6.25 \%$ in percentage of cases of anemia, this also adds a history of health condition in $4.7 \%$ in relation to urinary infections before pregnancy.

The newborn or the child who was born by a premature birth process as mentioned by RomeroMaldonado, Arroyo-Cabrales, \& Reyna-Ríos, 2012 suggests that they go back to cases in which children between 22 and 26 weeks of gestation they presented a 20 to $25 \%$ deficit in the elderly, this being a reason why the mental deficit was established with a 17 to $21 \%$ accordingly, the cerebral palsies can also be established which were in the 12 to $15 \%$ the affections due to Blindness and deafness are higher percentages occupied an equivalent to 5 and $8 \%$, and, 3 to $5 \%$ As Mendez \& Aramada puts it, 2012 in regard to children who were born prematurely are linked to a higher danger rate for contracting Hypothermia and early hypoglycemia as a result of the lack of development of the optimal and regular transition within the range of 12 hours of life, hypothermia 
and hypoglycemia can impair and jeopardize the difficulty of breathing In addition, we present other different pathogens or complications that in the case of premature children may contract as transient tachypnea or shortness of breath syndrome, this occurs in cases of late premature infants and also with a greater possibility that it may cause Many conditions and as a consequence of the lack of development of the pulmonary fluid and the low capacity of pulmonary surfactant, children born by preterm birth in relation to the corresponding gestational age can present some problems in their immune system compared to external premature infants and newborns are also unlike late premature infants, which in turn may also present certain abnormalities in their immunological maturity.

Thanks to the study carried out by Rodriguez, 2013, a resolution was reached in which the highest percentage of pregnant adolescents are located between 15 and 17 years of age, on the other hand it was estimated that $56 \%$ is linked to the teenager of 18 years of age and lower percentage range are taken by adolescents aged between 12 and 14 years of age with an equivalent to $34 \%$, within the social causes greater nature are linked to a lack of sexual orientation which is in percentage of the $30 \%, 23 \%$ is linked to family problems, factors such as poverty and family abuse are $20 \%$ in relation to these two aspects and 7\% in sexual abuse, one of the biggest risk factors for contracting Premature delivery lies in the process of bacterial infections caused by bacterial vaginitis. These cases occur in greater instances in women under 20 years of age. It is estimated that in those over premature births are linked by the conditions caused by bacterial vaginitis whereby symptoms occur around 34 and 36 weeks of pregnancy and on the other hand this was also a reason why their parental controls were not entirely optimally solved.

One of the most eventual complications of pregnant teenagers has also been linked to urinary tract infections, which in all cases have been treated at the José María Velasco Ibarra Hospital, it should be noted that these infections crucially affect the process of a normal delivery or pregnant being this factor by which a preterm birth is developed, so the only solution more suitable to avoid this type of cases is to follow to the letter and with due responsibility the parental control for this decrease fetal maternal morbidity, this would also help many pregnant teenagers become aware and serve them so they can continue their pregnant so safe at the same time motivating a perfect family planning for a good population growth in health, in one of Salvador's research, 2013 indicates that the factors of greatest risk or danger to a woman's maternal life are related to the premature delivery A rigorous retrospective, comparative and control study was followed, based on many of the anecdotes or clinical experiences that have been carried out by patients whose many deliveries were attended at the Cayetano Heredia National Hospital. Many of the danger factors are located in ages under 20 years of age, or that have a history of prematurity, irresponsible parental control, infections, early ruptures of the membranes, hemorrhages in childbirth, consequently, left as a result twin pregnancy or intrauterine death.

The magazine of the Clinic of the School of La Medina of the year 2016 announces that within the greatest risks in consideration of pre-term deliveries they are related to the fact that the pregnant woman has been affected in some later cases due to premature birth, which is why it is considered that there is an exhaustive parental control of the pregnancies in order to identify any type of latent risk or that may arise during the woman's pregnant period. Therefore, in this way many of the different risk factors could be avoided. The National Directorate of Maternity and Children establishes that effective primary prevention should be carried out in pregnant women in order to 
identify and thus be able to work to reduce risk factors, it is vitally important that women be given all the guidelines for a good lifestyle during your pregnant as they are good eating habits and the eventual and continuous check-up of gynecologists to solve or help any latent infection or that may occur in greater severity in order to help the woman linked to a treatment that gives solution if an infection is found, It is recommended that exams be performed before 20 weeks of gestation

\section{Materials and Methods}

In the investigation, the record of the medical records for pregnant adolescents with a threat of preterm birth with the ages of 10 to 19 years was implemented, tabulating these data and implementing in Excel the classification of variables for the development of the respective analysis, being This is supported by the respective permits of the corresponding authorities.

In the development of the research it was used as a formula for the calculation of sample for finite populations, with a universe of 786 adolescent patients whose ages are between 10 to 19 years, which were diagnosed as a threat of preterm birth during the January period as of December 2015; resulting in a sample of 251 patients who meet the terms requested for the investigation.

The formula for the calculation of the sample is specified below:

$$
\begin{aligned}
& \text { Nomenclatures } \\
& \mathrm{N}=\text { Total population } \\
& \mathrm{n}=\text { Sample size } \\
& \mathrm{z}=\text { Confidence level } \\
& \mathrm{p}=\text { probability in favor } \\
& \mathrm{q}=\text { probability against } \\
& \mathrm{e}=\text { Allowed error }
\end{aligned}
$$

\begin{tabular}{|c|c|c|}
\hline Variables & Definition & Indicator \\
\hline \multicolumn{3}{|l|}{ Dependent variable } \\
\hline Preterm Delivery & $\begin{array}{l}\text { Teen } 10 \text { to } 19 \text { years } \\
\text { pregnant }\end{array}$ & Influential factors \\
\hline \multicolumn{3}{|l|}{ Independent variables: } \\
\hline Age & $\begin{array}{l}\text { Years at the time of } \\
\text { investigation }\end{array}$ & Years old \\
\hline Prenatal Controls & Number of controls & One two Three \\
\hline History of preterm birth & $\begin{array}{l}\text { You have previously had } \\
\text { preterm birth }\end{array}$ & Yes / not \\
\hline $\begin{array}{l}\text { Obstetric diseases related to } \\
\text { pregnancy }\end{array}$ & $\begin{array}{l}\text { Complications-more } \\
\text { frequent }\end{array}$ & $\begin{array}{l}\text { Pre-eclampsia, Placenta previa, } \\
\text { Gestational diabetes. }\end{array}$ \\
\hline Gestational age & Product Exit Age & From 22 to 36 weeks completed \\
\hline $\begin{array}{l}\text { maternal diseases associated } \\
\text { with pregnancy }\end{array}$ & $\begin{array}{l}\text { Most frequent health } \\
\text { problem }\end{array}$ & $\begin{array}{l}\text { IVU, Vaginal infection, Diabetes, } \\
\text { Asthma }\end{array}$ \\
\hline
\end{tabular}

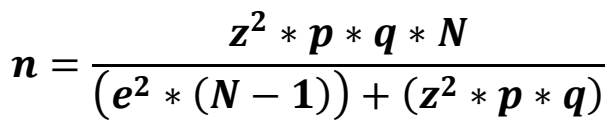

$$
\begin{aligned}
& n=\frac{1,96^{2} * 0,5 * 0,5 * 786}{\left(0,05^{2} *(785)\right)+\left(1,96^{2} * 0,5 * 0,5\right)} \\
& \boldsymbol{n}=\frac{754,87}{2.92}
\end{aligned}
$$

$\boldsymbol{n}=\mathbf{2 5 1}$ A representative sample of 251 people was selected.

The following table of variables was identified:

Table 1: Variable table 


\section{Results and Discussions}

For the ages of pregnant adolescent women with threats of preterm birth who have been treated at the Enrique C. Sotomayor Hospital, in the period from January to December 2015, the values indicating $1 \%$ of patients with ages between 10 to 12 years, $9 \%$ between 13 and 14 years old, these two groups are identified as those with the lowest preterm percentage of the patients, also observing that the highest range of patients with preterm is between 17 and 19 years old for Ecuador, an amount close to one fifth is that specified by age ranges of 15 to 16 years.

Table 2: Pregnant women with preterm birth threats attended, according to age.

\begin{tabular}{|l|c|c|}
\hline Data & Frequency & Percentage \\
\hline $10-12$ & 2 & $1 \%$ \\
\hline $13-14$ & 23 & $9 \%$ \\
\hline $15-16$ & 53 & $21 \%$ \\
\hline $17-19$ & 173 & $69 \%$ \\
\hline Total & 251 & $100 \%$ \\
\hline
\end{tabular}

Regarding the place of origin of pregnant adolescent women with threats of preterm delivery attended at the Enrique C. Sotomayor Hospital, in the period January to December 2015, it was obtained that $73 \%$ of the patients attended come from the urban sector, while a $17 \%$ of the marginal sector and a minimum of the rural sector.

Table 3: Pregnant women with preterm birth threats attended, according to origin.

\begin{tabular}{|l|c|c|}
\hline Procedure & Frequency & Percentage \\
\hline Rural & 25 & $10 \%$ \\
\hline Urban & 183 & $73 \%$ \\
\hline Urban-Marginal & 43 & $17 \%$ \\
\hline Total & 251 & $100 \%$ \\
\hline
\end{tabular}

\section{Procedure Frequency Percentage}

For the gestational age of pregnant adolescent women with threats of preterm birth who have been treated at the Enrique C. Sotomayor Hospital, in the period from January to December 2015 according to the period of care it is identified that a value of $74 \%$ of those attended are between week 31 to 36, this being the largest number of patients, contrasting with a lower number for patients between week 22 to 30 that reached a value of $36 \%$ of patients.

Table 4: Pregnant women with preterm birth threats attended, according to gestational age.

\begin{tabular}{|l|c|c|}
\hline Data & Frequency & \% \\
\hline $22-24$ & 13 & $5 \%$ \\
\hline $25-27$ & 25 & $10 \%$ \\
\hline $28-30$ & 52 & $21 \%$ \\
\hline $31-33$ & 66 & $26 \%$ \\
\hline $34-36$ & 95 & $38 \%$ \\
\hline Total & 251 & $100 \%$ \\
\hline
\end{tabular}


As a result in reference to the state of the product, the values of $38 \%$ live births with adequate health status were obtained, in addition to this it is gathered that $60 \%$ of the products are derived from another health institution and when the risk ends they are When discharged, only $2 \%$ of children born had serious complications resulting in death.

Table 5: Pregnant women with preterm birth threats attended, depending on product outcome.

\begin{tabular}{|l|l|l|}
\hline Data & Frequency & Percentage \\
\hline Patients with medical discharges & 150 & $60 \%$ \\
\hline Alive & 96 & $38 \%$ \\
\hline Dead & 5 & $2 \%$ \\
\hline Total & 251 & $100 \%$ \\
\hline
\end{tabular}

According to the number of prenatal controls identified for pregnant adolescent women with threats of preterm birth that have been treated at the Enrique C. Sotomayor Hospital, in the period January to December 2015, it was obtained that, the majority of patients presented minimal controls reaching a figure of $91 \%$ of these with a maximum of two controls, and only $9 \%$ of them developed greater controls without reaching 5 controls during their gestation stage.

Table 6: Pregnant women with preterm birth threats attended, depending on product outcome.

\begin{tabular}{|l|c|c|}
\hline Data & Frequency & Percentage \\
\hline $0-1$ & 97 & $39 \%$ \\
\hline $2-3$ & 131 & $52 \%$ \\
\hline $4-5$ & 23 & $9 \%$ \\
\hline more than 5 & 0 & $0 \%$ \\
\hline Total & 251 & $100 \%$ \\
\hline
\end{tabular}

Maternal diseases associated with pregnant teenage women with threats of preterm birth that have been treated at the Enrique C. Sotomayor Hospital, in the period from January to December 2015, variable values are identified, with greater emphasis on vaginal infections with $49 \%$, followed by anemia at a value of $21 \%$, UTIs with a value of $16 \%$, a value of $7 \%$ for diabetes and even $7 \%$ of patients without any condition.

Table 7: Pregnant women with preterm birth threats attended, depending on product outcome.

\begin{tabular}{|l|c|c|}
\hline Data & Frequency & Percentage \\
\hline Anemia & 53 & $21 \%$ \\
\hline IVU & 40 & $16 \%$ \\
\hline Diabetes & 18 & $7 \%$ \\
\hline Vaginal infection & 123 & $49 \%$ \\
\hline Asthma & 0 & $0 \%$ \\
\hline Does not present & 17 & $7 \%$ \\
\hline Total & 251 & $100 \%$ \\
\hline
\end{tabular}

Obstetric diseases associated with pregnant adolescent women with threats of preterm birth that have been treated at the Enrique C. Sotomayor Hospital, in the period January to December 2015, 
are identified in minimum values, with Preclampsia in 18\%, RPM in a $8 \%$ and Placenta previa in $7 \%$, obtaining a value greater than half of the patients who do not have obstetric diseases.

Table 8: Pregnant women with preterm birth threats attended, depending on product outcome.

\begin{tabular}{|l|c|c|}
\hline Data & Frequency & Percentage \\
\hline Previous placenta & 18 & $7 \%$ \\
\hline Preclamsia & 45 & $18 \%$ \\
\hline RPM & 20 & $8 \%$ \\
\hline Does not present & 160 & $64 \%$ \\
\hline Amniotic fluid disorder & 8 & $3 \%$ \\
\hline Total & 251 & $100 \%$ \\
\hline
\end{tabular}

The factors associated with preterm delivery of pregnant adolescent women with threats that have been treated at the Enrique C. Sotomayor Hospital, in the period January to December 2015, were identified with deficient values in birth controls by having $69 \%$ of low controls, with $13 \%$ vaginal bleeding, patients with a history of preterm delivery in 10\%, and RPM in $8 \%$.

Table 9: Pregnant women with preterm birth threats attended, depending on product outcome.

\begin{tabular}{|l|c|c|}
\hline Data & Frequency & Percentage \\
\hline History of preterm birth & 25 & $10 \%$ \\
\hline Poor prenatal controls & 173 & $69 \%$ \\
\hline By membrane rupture & 20 & $8 \%$ \\
\hline Vaginal bleeding & 32 & $13 \%$ \\
\hline Total & 251 & $100 \%$ \\
\hline
\end{tabular}

\section{Conclusions and Recommendations}

Regarding maternal risk factors in adolescents with the threat of preterm birth carried out at the Enrique Sotomayor Hospital, it was found that a large part of the adolescents did not consistently perform the prenatal control required in the period of gestational training, thereby increasing the incidence of neonatal maternal morbidity and mortality ; thus, it was also identified that the most frequent pathology in pregnant adolescents is urinary tract infections (UTIs), bacterial vaginitis present in the gestation period can be mentioned; Finally, pregnant adolescents whose age range is established between the ages of 17 and 19 were mostly patients who presented complications during the gestation period.

As a recommendation it is established to carry out multiple awareness campaigns for teenage pregnant women, in order to understand the importance of prenatal controls, and thereby reduce the incidence of complications during the gestation process; as well as, to carry out talks of sexual education for this it is possible to reduce the birth rate that year by year appears in the adolescents; By understanding the importance of prenatal check-ups, pregnant women will be able to carry out weekly check-ups and detect some risk factor in time, thus being able to significantly reduce future diseases or complications. 


\section{References}

[1] AFPA. (207). Analysis of the situation of teenage pregnancy in the Andean Area Countries. AFPA.

[2] Aguilera, N., \& Argote, G. (2014). Risk of spontaneous preterm labor and its relationship with stress and anxiety. Medical Sciences México.

[3] Barrera, F., \& Higuera, L. (2013). Pregnancy and teenage fertility. Fed developed.

[4] Barrera, S., Lina, M., \& Ospina, M. (2016). Factors associated with preterm birth in adolescents in Tunja, Boyacá. Virtual Magazine Catholic University of the North.

[5] Bendezú, G., Espinoza, D., \& Torres, R. (2016). Characteristics and risks of teenage pregnant women. Rev. peru. ginecol.

[6] Calderón, J. (2014). Factors associated with preterm birth. Medigra.

[7] Coffre, J. (2018). Factors that affect the threat of preterm birth in pregnant adolescents in the San Jacinto canton of Yaguachi. Journal of Investigative Nursing.

[8] Díaz, A. (2014). Obstetric risks in adolescent pregnancy: Comparative study of obstetric results. Sciel Cl.

[9] Díaz, A., Sanhueza, P., \& Yaksic, B. (2002). Obstetric risks in adolescent pregnancy and comparative studies of obstetric and perinatal outcomes with adult pregnant patients. Rev Chile Obsty Ginecol.

[10] Dides, C., \& Férnandez, C. (2014). First report on sexual health, reproductive health and human rights in Chile. UNFPA.

[11] García, O., \& González, S. (2018). Risk factors associated with teenage pregnant women. Mag. Cient. Med.

[12] Gómez, M. (2014). Introduction to the methodology of scientific research. Cordova: Bruges Publishing House.

[13] Guevara, D. (2015). Risk Factors Associated With Preterm Birth In The Alfredo Noboa Montenegro Hospital In Guaranda. Gynecological Magazine.

[14] Issler, J. (2011). Pregnancy in adolescence. Obstetrics magazine.

[15] Martínez, C., Díaz, Z., \& Romero, V. (2017). Risk factors associated with preterm birth in adolescents. Tabasco health.

[16] Matamala, P. (2014). Premature delivery. Obstetrics.

[17] Menendez, E., \& Amada, I. (2012). Pregnancy and its complications in the teenage mother. Cuban Journal of Obstetrics and Gynecology.

[18] Menendez, E., \& Amada, I. (2012). Pregnancy and its complications in the teenage mother. Cuban Journal of Obstetrics and Gynecology. Medic.

[19] MINSAL. (2010). Clinical guide: Prevention of premature delivery. Chile.

[20] OMS. (2012). Global Action Report on Premature Births.

[21] Ovalle, A., \& Kakarieka, E. (2012). Factors associated with premature delivery between 22 and 34 weeks in a public hospital in Santiago. Mag. Med. Chile.

[22] Ovalle, A., Rencoret, G., Fuentes, A., \& Morong, C. (2012). Factors associated with premature delivery between 22 and 34 weeks in a public hospital in Santiago.Mag med Chi.

[23] Oviedo, C., Plascencia, L., \& Nakashimida, A. (2007). Causes of preterm birth among teenage mothers. Obstetric Gynecology Mexico.

[24] Retureta, M., Rojas, A., \& Retureta, M. (2015). Risk factors for preterm birth in pregnant women of the Ciego de Ávila Municipality. Medisur.

[25] Reyes, O., Coello, E., Carrasco, M., Gonzalez, D., Mendoza, F., Mejía, R., . . García, A. (2016). Obstetric complications in adolescent adult women with or without associated risk factors. ImedPub Journals.

[26] Reyes, P., Navarrete, H., \& Serrano, C. (2015). Percentages of births and fertility rates in adolescents in Mexico: stratification and prioritization of municipalities with high risks. Ginecol Obst Mex. 
[27] Rodrigo, R., \& Hübne, M. (2013). Survival, viability and prognosis of preterm infants. Revista médica de Chile.

[28] Romero, M., Arroyo, C., \& Rios, R. (2012). Late premature consensus. Human Reproduction, pp 124-130. Medic.

[29] Salvador, J. (2013). Risk factors of preterm birth: Case-control study. Peruvian Journal of Gynecology and Obstetrics.

[30] Sampieri, H. (2013). Research methodology. Santiago: Mc. Graw Hill.

[31] Thomazini, I., Thomazini, S., \& Domingues, A. (2016). Risk factors related to Preterm Labor in pregnant adolescents. Globlal Nursing Magazine.

[32] Unicef. (2007). Teenage maternity in Latin America and the Caribbean: Trends, problems and challenges. Unicef.

[33] Welti, C. (2014). Demographic analysis of adolescent fertility in Mexico. Pap.pobl.

${ }^{*}$ Corresponding author.

E-mail address: jorge.dahern@ug.edu.ec/vicky.naream@ug.edu.ed

katherine.rodriguezb@ug.edu.ec/rocio.fonseca@ug.edu.ec/yomitayong@gmail.com 